\title{
Dealing with post-traumatic stress disorder in general practice
}

\author{
Suliman S, MA, Psychologist \\ MRC Anxiety Disorders Unit, Department of Psychiatry, Stellenbosch University \\ Stein DJ, MD, PhD, Psychiatrist \\ Department of Psychiatry and Mental Health, University of Cape Town \\ Correspondence to: Sharain Suliman, e-mail: sharain@sun.ac.za \\ Keywords: post-traumatic stress disorder, general practice
}

\begin{abstract}
Traumatic experiences are prevalent in South Africa and may result in psychiatric disorders such as post-traumatic stress disorder (PTSD). PTSD is accompanied by a range of psychobiological alterations, including changes in brain structure and functioning. General practitioners have an important role to play in identifying and assisting those in need of help. Efficacious psychotherapies and pharmacotherapies are available for PTSD, i.e. cognitive behavioural therapy and selective serotonin reuptake inhibitors.
\end{abstract}

(c) Medpharm

S Afr Fam Pract 2012;54(4):308-311

\section{Introduction}

The South African Stress and Health Study has estimated that $75 \%$ of adult South Africans have experienced a traumatic event, such as a physical or sexual assault, motor vehicle accident or disaster, i.e. fire or flood, at some point in their lives. ${ }^{1}$ Although responses to these events vary greatly and the majority of people recover on their own, some people develop longer-lasting problems, such as posttraumatic stress disorder (PTSD) or depression. Lifetime rates of PTSD have been estimated to be approximately $2.3 \%$ in South African community samples ${ }^{2}$ and prevalence may be higher in primary healthcare populations.

The Diagnostic and Statistical Manual of Mental DisordersIV-TR (DSM-IV-TR) ${ }^{3}$ diagnosis of PTSD requires that the event involves an actual or threatened death or serious injury (real or perceived) to self or others, and that the event evokes feelings of fear, helplessness or horror in the person (Criterion A). Other criteria include at least one symptom from the re-experiencing cluster (Criterion B: Distressing recollections of the event; upsetting dreams; acting or feeling as if the event is recurring and psychological reactivity on exposure to reminders of the event); three from the avoidance cluster (Criterion C: Efforts to avoid reminders of the event, i.e. thoughts, feelings, activities, places or people; inability to remember parts of the event; diminished interest in activities; feelings of detachment from others; restricted range of affect and a sense of a foreshortened future); and two from the hyperarousal cluster (Criterion D: Difficulty sleeping; increased anger or irritability; difficulty concentrating; hypervigilance and exaggerated startle response). Symptoms need to be present for at least one month, and cause significant distress or impairment in social, occupational or other important areas of functioning. DSM-5 criteria have not yet been finalised, but will be slightly different.

The response to stress includes numerous neurochemical changes. PTSD is characterised by disruptions in these processes, ${ }^{4}$ including concomitant alterations in cognitiveaffective function, e.g. difficulties with memory and a startle response, and brain structure, e.g. decreased hippocampal volume. The precise molecular disruptions in PTSD remain to be fully characterised but include changes in hormones, e.g. glucocorticoids; neurotransmitters, e.g. monoamines; and neuroplasticity pathways, e.g. brain-derived neurotrophic factor. Given the brain's plasticity, some of these changes may be reversible. Notably, while some molecular changes in PTSD may reflect the consequences of trauma, others may comprise pre-existing vulnerability factors. ${ }^{5}$

Although some trauma survivors seek psychological or psychiatric treatment, usually the majority present to general practitioners ${ }^{6}$ with general health complaints. ${ }^{7.8}$ Traumatised patients have been noted to visit physicians four times as often as nontraumatised ones. ${ }^{9}$ Survivors of childhood sexual abuse report more somatic complaints and are more likely to have a mental health, pain disorder or general medical diagnosis. ${ }^{7}$

As a result of the stigma and shame surrounding many traumatic events, e.g. sexual abuse, as well as that surrounding mental health problems, individuals with 
PTSD might not even mention the trauma exposure to their clinicians. ${ }^{10,11}$ As such PTSD and related conditions are often under-diagnosed, making it important for healthcare providers to ask routinely whether the patient has experienced a traumatic event, and if so, to screen for PTSD. ${ }^{10,12-14}$ Notably, healthcare providers who record more mental health diagnoses than their colleagues have reported decreased health expenditures and in-patient medical hospitalisations among their patients. ${ }^{15}$

\section{Co-morbidity}

PTSD is associated with significant functional impairment. Often, it co-occurs with other psychiatric disorders, particularly depression and substance-use disorders. A USA community study found that significant depressive symptomatology affects almost $50 \%$ of persons diagnosed with PTSD, and that the prevalence of alcohol-use disorders in individuals with PTSD is $52 \%$ for men and $30 \%$ for women. ${ }^{6}$ The fact that a range of different conditions are associated with trauma has contributed to the proposal of a separate category of trauma- and stress-related disorders in DSM-5.

\section{Management}

Although debriefing and benzodiazepines have often been used in the acute aftermath of exposure to a trauma, current guidelines suggest that these interventions should be avoided. ${ }^{16}$ Acute interventions should focus on promoting a sense of safety, calm, self- and community efficacy, connectedness and hope. ${ }^{17}$

Once PTSD has been diagnosed, appropriate interventions should be made. Psycho-education is a critical step, as it helps to empower patients to understand PTSD, its development, perpetuation and consequences. It also offers tools that help with coping. The patient's view of PTSD should be explored. A collaborative approach to choosing efficacious psychotherapy and pharmacotherapy options can then be adopted.

The psychological treatment with the best evidence for efficacy in PTSD is trauma-focused cognitive-behaviourial therapy (CBT). ${ }^{18,19}$ Trauma-focused CBT involves gradual repeated exposure to memories and situations associated with the traumatic event (that although objectively safe, elicits anxiety or is avoided) through imagination, narrative or in vivo exposure, and gradually challenging maladaptive trauma-related appraisals. ${ }^{20}$ Although the underlying mechanisms for this have not been elucidated, eye movement desensitisation and reprocessing therapy has also shown some promise.

First-line drug treatments for PTSD include selective serotonin reuptake inhibitors and the selective norepinephrine reuptake inhibitor, venlafaxine. ${ }^{21,22}$ Second-line treatments include the newer antidepressants and tricyclic antidepressants. Third-line treatment is monoamine oxidase inhibitors. In treatment-resistant cases, atypical antipsychotics, in conjunction with antidepressants, have been shown to be beneficial. ${ }^{23,24}$

\section{Summary}

PTSD is a common mental disorder that is often associated with high levels of disability and co-morbid conditions. Numerous psychobiological alterations accompany PTSD. Primary healthcare providers are often the first and only source of advice and support for patients suffering from PTSD. Appropriate intervention by primary healthcare providers may improve treatment outcomes.

\section{References}

1. Williams SL, Williams DR, Stein DJ, et al. Multiple traumatic events and psychological distress: The South Africa Stress and Health Study. J Trauma Stress. 2007;20(5):845-855.

2. Stein DJ, Seedat S, Herman A, et al. Lifetime prevalence of psychiatric disorders in South Africa. Br J Psychiatry. 2008;192(2):112-117.

3. American Psychiatric Association. Diagnostic and statistical manual of mental disorders. $4^{\text {th }}$ ed. Washington, DC: American Psychiatric Association Press; 2000.

4. Southwick SM, Davis LL, Aikins DE, et al. Neurobiological alterations associated with PTSD. In: Friedman MJ, Keane TM, Resick PA, editors. Handbook of PTSD: science and practice. New York: Guilford, 2007;p. 166-189.

5. Stein DJ, Cloitre M, Nemeroff CB, et al. Cape Town consensus on posttraumatic stress disorder. CNS Spectr. 2009;14(1 Suppl 1):52-58.

6. Kessler RC, Sonnega A, Bromet E, et al. Posttraumatic stress disorder in the National Comorbidity Survey. Arch Gen Psychiatry. 1995;52(12):1048-1060.

7. Engel CC, Liu X, Mccarthy BD, et al. Relationship of physical symptoms to posttraumatic stress disorder among veterans seeking care for Gulf War-related health concerns. Psychosom Med. 2000;62(6):739-745.

8. Fogarty $\mathrm{CT}$, Sharma S, Chetty VK, Culpepper L. Mental health conditions are associated with increased health care utilization among urban family medicine patients. Am Board Fam Med. 2008;21(5):398-407.

9. Ballenger JC, Davidson JR, Lecrubier $Y$, et al. Consensus statement on posttraumatic stress disorder from the International Consensus Group on Depression and Anxiety. J Clin Psychiatry. 2000;61 Suppl 5:60-66.

10. Forbes D, Creamer MC, Phelps AJ, et al. Treating adults with acute stress disorder and post-traumatic stress disorder in general practice: a clinical update. Med J Aust. 2007;187(2):120-123.

11. Meredith LS, Eisenman DP, Green BL, et al. System factors affect the recognition and management of post-traumatic stress disorder by primary care clinicians. Med Care. 2009;47(6):686-694.

12. Carey PD, Stein DJ, Zungu-Dirwayi N, Seedat S. Trauma and posttraumatic stress disorder in an urban Xhosa primary care population: prevalence, comorbidity, and service use patterns. J Nerv Ment Dis. 2003;191(4):230-236.

13. Clardie S. Post-traumatic stress disorder within a primary care setting: effectively and sensitively responding to sexual trauma survivors. WMJ. 2004;103(6):73-77.

14. Marais A, de Villiers PT, Miller AT, Stein D. Domestic violence in patients visiting general practitioners - prevalence, phenomenology, and association with psychopathology. S Afr Med J.1999;89(6):635-640.

15. Campbell TL, Franks P, Fiscella $\mathrm{K}$, et al. Do physicians who diagnose more mental health disorders generate lower health care costs? J Fam Pract. 2000;49(4):305-310.

16. Rose S, Bisson J, Churchill R, Wessely S. Psychological debriefing for preventing 
post traumatic stress disorder (PTSD). [Cochrane review]. In the Cochrane Library, Issue 2, 2002. Oxford: Update Software.

17. Hobfoll SE, Watson P, Bell CC, et al. Five essential elements of immediate and mid-term mass trauma intervention: empirical evidence. Psychiatry. 2007;70(4):283-315

18. Bisson J, Andrew M. Psychological treatment of post-traumatic stress disorder. [Cochrane review]. In the Cochrane Library, Issue 3, 2007. Oxford: Update Software.

19. Ponniah K, Hollon SD. Empirically supported psychological treatments for adult acute stress disorder and posttraumatic stress disorder: a review. Depression and Anxiety. 2009;26(12):1086-1109.

20. Cahill SP, Rothbaum BO, Resick PA, Follette VM. Cognitive-behavioural therapy for adults. $2^{\text {nd }}$ ed. In: Foa EB, Keane TM, Friedman MJ, Cohen JA, editors. Effective treatments for PTSD. New York: Guilford Press, 2009; p. 139-222.

21. Bisson Jl. Post-traumatic stress disorder. BMJ. 2007;334(7597):789-793.

22. Ipser JC, Stein DJ. Evidence-based pharmacotherapy of post-traumatic stress disorder. Int J Neuropsychopharmacol. 2012;15(6):825-840.

23. Ahearn $E P$, Juergens $T$, Cordes $T$, et al. A review of atypical antipsychotic medications for posttraumatic stress disorder. Int Clin Psychopharmacol. 2011;26(4):193-200.

24. Ipser JC, Carey P, Dhansay Y, et al. Pharmacotherapy augmentation strategies in treatment-resistant anxiety disorders. [Cochrane review]. In the Cochrane Library, Issue 1, 2007. Oxford: Update Software.

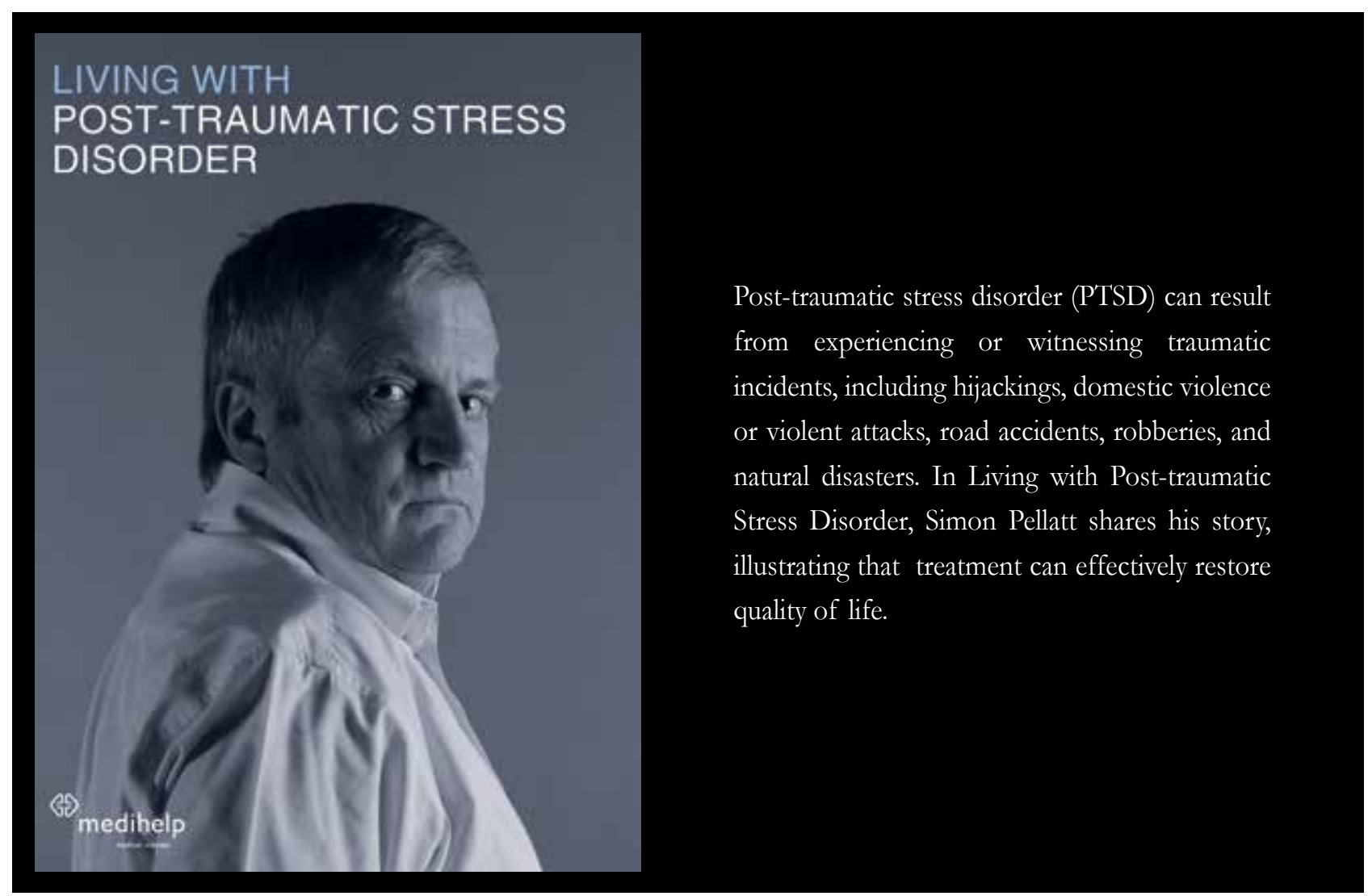

